\title{
What is Individualism in Social Ontology? Ontological Individualism vs. Anchor Individualism
}

\author{
BRIAN EPSTEIN
}

\author{
forthcoming in Rethinking the Individualism/Holism \\ Debate: Essays in the Philosophy of Social Science, \\ Finn Collin and Julie Zahle, eds. \\ Dordrecht: Springer, 2014
}

Individualists about social ontology hold that social facts are "built out of" facts about individuals. In this paper, I argue that there are two distinct kinds of individualism about social ontology, two different ways individual people might be the metaphysical "builders" of the social world. The familiar kind is ontological individualism. This is the thesis that social facts supervene on, or are exhaustively grounded by, facts about individual people. What I call anchor individualism is the alternative thesis that facts about individuals put in place the conditions for a social entity to exist, or the conditions for something to have a social property. Examples include conventionalist theories of the social world, such as David Hume's theories of promises, money, and government, and collective acceptance theories, such as John Searle's theory of institutional facts. Anchor individualism is often conflated with ontological individualism. But in fact, the two theses are in tension with one another: if one of these kinds of individualism is true, then the other is very unlikely to be. My aim in this paper is to clarify both, and argue that they should be sharply distinguished from one another.

It is widely recognized that methodological individualism - a topic long debated in the social sciences - consists of two different theses. Explanatory individualism is a thesis about the methodology of the social sciences: it holds that explanations of social facts or phenomena should be individualistic. That 
is, they should be given in terms of individual people and certain relations between individuals. Ontological individualism, on the other hand, is a thesis about the nature or metaphysics of social facts or phenomena. It holds that social facts or phenomena are exhaustively built out of, or depend on, individualistic ones. To put it in the familiar way, ontological individualism is the thesis that there is nothing to social facts "over and above" facts about individuals and certain relations between individuals. In recent decades, these two theses have been thoroughly disentangled from one another. Many theorists endorse explanatory individualism, while many others deny it. But nearly everyone agrees with ontological individualism, believing it to be the only alternative to the crazy idea that social facts are autonomous spirits, lurking in a separate metaphysical realm.

In recent work, I have challenged ontological individualism. The thesis is not as trivial as many people assume, nor is it the only alternative to a crazy metaphysic of the social. In fact, I argue in Epstein 2009 that even on a most charitable interpretation, the thesis is false.

There are, however, two quite different ways the social world might "depend on" or be "built out of" facts about people. The literature on ontological individualism - my 2009 article included — only notices one of them. My aim in this piece is to distinguish ontological individualism from a different thesis about the role of individuals in "building" the social world. This second thesis I will call anchor individualism. Both are metaphysical theses about the relation of social facts to facts about individual people.

Ontological individualism is a thesis about the composition, supervenience, exhaustive determination, or grounding of social facts by individualistic ones. As Harold Kincaid puts it:

Social wholes are both composed of individuals and determined by their actions... Individuals determine the social world in the intuitive sense that once all the relevant facts (expressed in the preferred individualist vocabulary) about individuals are set, then so too are all the facts about social entities, events, etc. Or, to put this idea in terms of supervenient properties, the social supervenes on the individual in 
the sense that any two social domains exactly alike in terms of the individuals and individual relations composing them would share the same social properties. ${ }^{1}$

In short, ontological individualism is the thesis that social facts supervene on or are exhaustively grounded by individualistic ones. A different way of understanding the metaphysical relation between individuals and the social world, however, does not take social facts to be composed of or supervenient on the individual. Rather, it derives from the idea that things have social properties in virtue of people conceiving of them in a certain way, or treating them in a certain way, or acting in a certain way. This alternative thesis is that facts about individuals put in place the conditions for a social entity to exist, or the conditions for something to have a social property. Although this alternative is less commonly discussed, it is at the heart of many contemporary approaches to the ontology of the social world, and it has deep historical roots. To coin a new term, I will call this “putting in place” relation 'anchoring', a term I will define more carefully in Section 2. Anchor individualism, then, is the thesis that social facts are exhaustively anchored by individualistic ones. Facts about individuals and certain relations between them, the thesis holds, set up the conventions, do the projecting, or otherwise anchor the social world.

Although ontological individualism and anchor individualism are often conflated, they are independent of one another: it is coherent to endorse one while denying the other. That is not to say that they are unrelated. In fact, they are in tension with one another. If one of these kinds of individualism is true, then the other is very unlikely to be. My aim in this paper is to describe the two theses and identify the elements that must be clarified if the theses are to be pinned down, propose that the theses are distinct, and point out the tension between them. In this paper, I will not address the truth or falsity of either thesis.

${ }^{1}$ Kincaid 1986, p. 499 


\section{Ontological individualism}

Ontological individualism is a thesis in the field known as "inter-level metaphysics." Inter-level metaphysics is concerned with the relations between objects, events, properties, and facts at different "levels." Some of the problems of inter-level metaphysics have to do with causation at different levels, such as whether it is coherent to take a high-level event as a cause for a low-level one, ${ }^{2}$ as in the proposition, Jane's belief that there was a fly on her nose caused such-and-such a neuron to fire.

A different set of problems of inter-level metaphysics has to do with non-causal determination. Jane's belief that there was a fly on her nose had certain causal consequences. But the belief itself is arguably "built out of" her neural states being in a certain pattern. A large family of terms is used to describe different ways that one entity may be "built out of" another: the belief is composed of neural states, the belief is constituted by neural states, the neural states realize the belief, the belief emerges from the neural states, the belief is grounded by the neural states, or the belief supervenes on neural states. ${ }^{3}$ Part of the task of clarifying ontological individualism is deciding which of these "building" relations are the pertinent ones.

To argue that high-level entities like belief are "built out of" low-level entities like neural states, there are several projects we might pursue. One is to consider them token-by-token: what particular pattern of neural states grounds Jane's particular belief about the fly? Another is to consider them type-by-type: what type of pattern of neural states in a person's mind grounds a belief in that person that she has a fly on her nose? Both of these, however, are often difficult or impossible to answer, and anyway involve more detail than we need. A more straightforward project is to consider the relation between the high-level and low-level domains as a whole, or between sets of facts or properties at one level and sets of facts or properties at another. For instance,

${ }^{2}$ These problems arise when we assume - plausibly enough - causal closure of the physical and a lack of widespread causal overdetermination. See Kim 1998, p. 2

${ }^{3}$ See Bennett 2011, p. 81 
we might just argue that all of a person's mental states in general — including beliefs, desires, and so on - are "built out of” that person's neural states. This is a generic thesis about the determination of the whole set of mental states, somehow or other, out of a whole set of neural states, without trying to match a particular type of desire with a particular type of neural state.

This generic strategy is what social theorists employ in advocating ontological individualism. Ontological individualism does not require that we give the individualistic properties that correspond to each social property, like being an investment bank, being President of the U.S., or having cashed a check. Instead, ontological individualism is the general thesis that the social world is "built" out of an "individualistic base," or that social facts in general are built out of facts about individual people.

That is a very rough way of putting the thesis, leaving many things vague. What, for instance, counts as the "individualistic base," or the "facts about individual people”? Do these include people's mental properties, their physical properties, and/or certain relations between them? Different versions of the thesis of ontological individualism will take positions on this. Some theorists hold that social facts are built out of psychological states of individuals. Others hold that they are built out of both psychological states and certain relational properties between them. Still others hold that they are built out of behaviors, activities, or practices.

Similarly, we might ask which "building" relation is claimed to hold, between the social world and the individualistic base. Are social things composed out of individual people? Or instead, are social facts grounded by individualistic facts? And further, we might ask which "social facts" the thesis is about. Institutions? Artifacts? Groups?

In light of these ambiguities, it is more accurate to think of ontological individualism as a family of theses rather than a single one, or else as a very vague thesis that needs to be made precise in order to be understood and assessed. Ontological individualism is a thesis about non-causal determination in inter-level metaphysics, in particular, about some "exhaustive building" relation between individual-level stuff and social-level stuff. To be more 
precise than this, however, we need to say more about these three topics:

(1) What the "exhaustive building" relation is, which is claimed to hold between the individualistic base and the social level;

(2) What the individualistic base is: individual people, their mental states, their actions, habits, or practices, various relations among them, etc.; and,

(3) What is included in the social level is: the facts, events, objects, and properties held to be "built" out of the base.

I will discuss each of these in turn, with the aim of raising the key issues, not resolving a single correct response for each.

\subsection{The "exhaustive building" relation}

Many theorists, in discussing ontological individualism, speak of what the social world "consists of." For instance, in a well-known 1968 paper Steven Lukes says, "Society consists of people. Groups consist of people. Institutions consist of people plus roles and rules." " Geoffrey Hodgson, in a 2007 paper, uses the same term to make a different claim: "For reasons that will become clearer below, it is crucial whether it is claimed that the social world simply consists of individuals, or of individuals and interactive relations between them." ${ }^{5}$ In the next section I will discuss things like interactive relations between individuals, but let us begin by noticing that we have to do better than "consists of."

There are many senses in which one thing might "consist of" another. A promissory note might consist of its material constitution, e.g., a blob of paper and ink. Or it might consist of its parts, or it might consist of its wording, or it might consist of the promise with which it was issued, or it might consist of its essential properties, and so on. Another problem with "consists of" is that it seems only to apply to objects, not properties or facts. It may not even be grammatical to speak of a social property like being President or a social fact

\footnotetext{
${ }^{4}$ Lukes 1968, p. 451

${ }^{5}$ Hodgson 2007, p. 215
} 
like Obama is President "consisting of" properties of individuals or facts about individuals. We need a more precise notion.

The most sophisticated treatments of ontological individualism, like Harold Kincaid's I quoted above, have latched onto supervenience. Supervenience is a family of relations, designed expressly for clarifying non-causal determination between sets of entities at one level and sets of entities at another. Usually, supervenience is understood as a relation between two sets of properties - chemical properties and physical properties, mental properties and neural properties, social properties and individualistic properties, and so on. However, it can relatively easily be adapted to relate sets of facts, events, or objects, instead of properties.

There are many forms of supervenience, but the most pertinent to ontological individualism is global supervenience. ${ }^{6}$ Consider two sets of properties, a high-level set of properties A, and a low-level set of properties B. Intuitively, to say that A globally supervenes on B is to say that if we fix all of the B-properties in the whole world, then that suffices to fix all the A-properties in the world as well. To say that the chemical properties globally supervene on the properties of microphysics is to say that if it is fixed what all the microphysical properties are, everywhere in the world, then there is no more work to do in fixing the chemical properties. They are already fixed.

To be more precise still, the notion of global supervenience is cashed out in terms of possible worlds. A common formulation is:

A-properties globally supervene on B-properties if and only if for any worlds $w 1$ and $w 2$, if $w 1$ and w2 have exactly the same worldwide pattern of distribution of B-properties, then they have exactly the same world-wide pattern of distribution of A-properties. ${ }^{7}$

Applying the notion to ontological individualism, suppose we have come

\footnotetext{
${ }^{6}$ Currie 1984 points out that local supervenience fails, for social properties. See Epstein 2008 and Epstein 2011 for refinement of this point.

7 McLaughlin and Bennett 2005. There are, in fact, several versions of global supervenience, but their differences are not important for our purposes; cf. Epstein 2009.
} 
to resolution on what the social properties are and what the individualistic properties are. To say that the social properties globally supervene on the individualistic properties is to say that once the worldwide distribution of individualistic properties, present and historical, is fixed, that already fixes the worldwide distribution of social properties. This is an intuitive way to capture the idea that there is nothing to the social "over and above" the individualistic.

Global supervenience is a very minimal relation. That is, if it does hold between two sets, there does not need to be any way of identifying which individualistic properties determine which social properties in which worlds. And it certainly does not imply anything about individualistic explanation of social phenomena. More technically, supervenience is also only a claim about co-variance between worlds - that is, if one world has a different worldwide distribution pattern of social properties than another, then the two worlds must have different worldwide distribution patterns of individualistic properties.

This minimal-ness is both an advantage and disadvantage to global supervenience, as an understanding of the "exhaustive building" relation in ontological individualism. The advantage is that it sets the bar nice and low. If global supervenience does hold, it provides at least some sense in which the social properties depend on the individualistic ones, without requiring that each social property correspond to particular individualistic ones. The disadvantage, however, is that the bar is so low, that it can barely be counted as saying that the social world is determined by the individualistic, or is built out of the individualistic. Supervenience is only a claim about co-variances: changes in the social must be accompanied by changes in the individualistic. Many philosophers have recently argued that we need more. Just because two sets of properties co-vary in the right way does not suffice to show that one is built out of the other. Thus it is not quite right to understand the "exhaustive building" relation as supervenience. Instead, all the different supervenience relations are best understood as diagnostic tools, like X-ray or MRI machines, for assessing when an exhaustive building relation is in place.

Increasingly prominent among metaphysicians is a new approach to basic 
"building" relation: what is being called the grounding relation. ${ }^{8}$ The fact Obama is President, for instance, is grounded by a set of other facts, such as the fact that he is at least 35 years old, that he won a majority of votes by the Electoral College, and that he took the appropriate oath of office. There are other facts that his being President might co-vary with, but this set of grounding facts is the metaphysical basis for the fact that he is President.

The literature on grounding is reasonably new. It is promising, because it has the potential to help clarify when one fact is the case in virtue of another fact being the case. But philosophers are still working out the details of the idea. Moreover, grounding alone is not enough to be the "exhaustive building" relation we need. The grounding relation holds between some fact $\mathrm{F}$ and a set of facts $\{\mathrm{G} 1, \mathrm{G} 2, \ldots\}$ that together ground $\mathrm{F}$. But remember that ontological individualism is a generic claim about the relation of the whole set of social facts to the whole set of individualistic facts. That is what global supervenience is trying to capture - this generic dependence of a whole set of facts on another whole set of facts. Thus the grounding relation should be seen as a replacement for the "covariance" relation that is part of a supervenience claim. To capture the idea that the entire set of social facts is "exhaustively grounded" by individualistic facts, we will need to construct something like the supervenience relation, but using grounding as a building-block rather than covariance. $^{9}$

All that is to say that for the moment, global supervenience is a reasonable way to understand the "exhaustive building" relation in ontological individualism. But further work will likely permit global supervenience to be replaced with an improved understanding.

\subsection{The individualistic base}

A more difficult problem is pinning down what the individualistic base is, in a claim of ontological individualism. Consider again the quotation from

\footnotetext{
${ }^{8}$ Fine 2001; Rosen 2010; Schaffer 2009

${ }^{9}$ Correia 2005 develops a number of candidates.
} 
Hodgson: "it is crucial whether it is claimed that the social world simply consists of individuals, or of individuals and interactive relations between them." As I discussed in the last section, we would do better to replace 'consists of' with 'globally supervenes on'. Putting it in these terms, Hodgson can be read as suggesting that there is a crucial difference between the claims:

(a) The social world globally supervenes on individuals, and

(b) The social world globally supervenes on individuals and interactive relations between them.

This is a claim about the "individualistic base" for the social world. When the ontological individualist says that the social supervenes on the individualistic, how should 'individualistic' be understood?

Hodgson's argument is useful to consider, because it is a widely held perspective on individualism. His basic line is this. If we only consider individuals in isolation, we do not have the complete building blocks for the social, since that would neglect their interactions. Furthermore, when we talk about "interactive relations," we need to think about two different things: the individual interactions between pairs of people, and also the social relations that people stand in. For instance, if person $\mathrm{X}$ purchases something from you, $\mathrm{X}$ interacts one-to-one with you, but $\mathrm{X}$ also makes use of a pricing mechanism, or monetary institution, which are social structures. Thus $\mathrm{X}$ 's "interactive relations” involve both X's relations to other individuals and X's relations to social structures.

What is a social structure? Hodgson does not endorse the idea that social structures lurk in some autonomous metaphysical realm. Instead, he takes them to be "emergent" from interacting individuals:

Some social scientists may uphold that social structures involve more than relations between individuals (where such relations also include social positions)... But this would be mistake. A danger here is to reify social structure as something more than an interacting pattern of individuals, which would exist even if the individuals all disappeared. Social structures are essentially groups of interacting social individuals, possibly including social positions, and with emergent 


\section{properties resulting from this interaction. ${ }^{10}$}

If this is correct, then X's relations to social structures are really multi-place relations holding of the whole population, of which $\mathrm{X}$ is a member. These multi-place relations emerge from (and hence supervene on) patterns of one-to-one interaction in the population as a whole. In other words, a first pass at interpreting (b) is:

(b’) The social world globally supervenes on individuals and one-to-one interactive relations among the whole population.

In short, Hodgson's thought is that ontological individualism is false if we just consider isolated individuals, but it is true if we add the worldwide distribution of one-to-one interactive relations between people as well.

Hodgson's perspective seems plausible, and versions of it are widely held. However, it has several problems. First, (b') is somewhat redundant. Global supervenience is already a claim about the spread of properties over the whole world, including the whole population. So (b') is the same as:

(b') The social world globally supervenes on individuals and one-to-one interactive relations.

Second, supervenience is most clearly understood as a relation between properties, not sets of objects. But (a) is written in terms of objects, and (b) (b') involve a mix of objects and relations. To make the claims grammatical, we should rewrite them in terms of sets of properties. ${ }^{11}$

${ }^{10}$ Hodgson 2007, p. 221. It is not clear from Hodgson's discussion what work is done by "possibly including social positions." See Zahle 2006, pp. 331-34 for an interesting discussion of the debate over "role predicates" in ontological individualism.

${ }^{11}$ Or at least cash out a different notion of supervenience that applies to objects. But converting the relata to properties is easier. A simple trick can be used to include facts, objects, etc., while treating supervenience as a relation between properties. Instead of fact $F$, we can substitute the property being such that $F$. Instead of object $x$, we can substitute one or more of the following: (a) the property being such that $x$ exists, (b) the set of intrinsic properties of $x$, (c) the set of properties being such that $x$ is $P$, for all intrinsic properties $P$ that $x$ has. Thinking in this way has the advantage of forcing us to clarify what we mean when we put "individual people” into the base. 
Third and by far most significant, what count as the "one-to-one interactive relations"? Claim (a) is not hard to make sense of. To do so, we only need to distinguish intrinsic from extrinsic properties. An intrinsic property I have is being six feet two inches tall; among the extrinsic properties I have are being taller than Barack Obama, being a citizen of the United States, and being such that Spain is on the verge of defaulting on its sovereign debt. ${ }^{12}$ A person's intrinsic properties are those she has in isolation from the rest of the world, properties like her neural states, bodily structure, physical behaviors, etc. (Of course, a person's neural states might have been caused by external factors, but do not ontologically depend on those. $)^{13}$ When we talk about "supervening on individuals" in thesis (a), we presumably mean on intrinsic properties of individuals. Hodgson asserts, in objecting to (a), that intrinsic properties of individuals do not suffice as the supervenience base for social properties.

However, merely pointing out that social properties depend on some “interactive relations," as Hodgson does, fails to establish that (a) is mistaken. After all, there are a great many relations between pairs of individuals that themselves supervene on the intrinsic properties on the members of the pair. Consider, for instance, the following three facts:

(F1) Bob is four inches taller than Carol.

(F2) Bob is 6 feet tall.

(F3) Carol is 5 foot 8.

Fact (F1) is that the two-place relation is four inches taller than holds between Bob and Carol. Facts (F2) and (F3) are that intrinsic properties hold of Bob and Carol, respectively. But of course, there is nothing more to (F1) than the respective facts about Bob and Carol's heights. That is to say, just because we have added relations on top of intrinsic properties does not mean we have augmented the supervenience base.

Indeed, it is not obvious that even facts like the following fail to supervene

\footnotetext{
${ }^{12}$ At least, as of mid-June 2012.

${ }^{13}$ On intrinsic vs. extrinsic properties, see Weatherson 2006 and the referenced literature. It also has a nice discussion of relational properties versus extrinsic properties.
} 
on the intrinsic properties of individuals: ${ }^{14}$

(F5) Bob and Carol played a repeated ultimatum game against one another.

(F6) Bob acquired his cognitive apparatus through socialization and education.

Hodgson, for instance, points out that a game involves norms and rules, and also that the preferences at the outset are socially conditioned. Thus he concludes that we need social relations, not just intrinsic properties of individuals. But this inference is mistaken. Facts (F5) and (F6) might be like (F1), supervening on the intrinsic properties of Bob and Carol, or else on the intrinsic properties of the population as a whole.

That is not to say that (a) is the best interpretation of ontological individualism. In fact, if ontological individualism is to have a chance of being true, the ontological individualist surely needs to include certain extrinsic properties in the "individualistic base.” But an argument like Hodgson's does not show it. It neglects the crucial task of delineating exactly which extrinsic properties and relations must be added to the base, and fails to explain the shortcomings of a base that includes only the intrinsic properties of individuals.

Here are some better reasons for expanding the individualistic base, to include certain extrinsic properties of individuals. Economic exchanges would not occur without bundles of goods, so perhaps having such-and-such a bundle of goods should be counted as an individualistic property. Communication between two people cannot occur without a physical medium, so perhaps properties of the air between us should be somehow included among our individualistic ones. Many people think that having such-and-such a belief is an extrinsic property, so perhaps extrinsic attitudes should count as "individualistic." 15 Or perhaps the way to go is to include among the "individualistic" properties not just those that are intrinsic to an individual, but properties that are intrinsic to a pair of individuals acting and interacting with

\footnotetext{
14 Hodgson 2007, p. 218

15 The idea comes from Putnam 1975. Much of Pettit 1993 aims to accommodate an “externalist” theory of attitudes.
} 
one another.

Any or all of these may be part of an account of the individualistic base. Resolving the "individualistic base" is the key — and perhaps most overlooked - part of clarifying ontological individualism. On the one hand, I have pointed out that arguments like Hodgson's fail to challenge a very narrow interpretation of the individualistic. They do not say enough about "interactive relations" to show that intrinsic properties of the individuals in the population are inadequate for grounding the social. On the other hand, the examples of exchange, communication, and so on, do suggest that intrinsic properties of individuals are inadequate for grounding the social.

The uncharitable interpreter will take exchange, communication, and so on, to be counterexamples to ontological individualism. The charitable interpreter will look for ways to expand the set of properties that count as "individualistic," so as to include certain extrinsic properties. Still, even the charitable interpreter cannot just take every extrinsic property of individuals to be individualistic. You, for instance, have the extrinsic property being such that Spain is near default on its sovereign debt. That is not plausibly an individualistic property of yours. Nor can the ontological individualist assume, as Hodgson does, that "social structures" are emergent properties of patterns of individual interaction. That is little more than a restatement of a thesis of ontological individualism itself. Instead, the ontological individualist needs to clarify which properties count as the individualistic ones, preferably for independent reasons, and then proceed to show that the social properties globally supervene on them.

\subsection{The social}

The third part to clarifying ontological individualism is to pin down what counts as the social world, that is, what is claimed to be "exhaustively grounded" by the individualistic base. Relative to the other two, this is the easy one.

Now, it is surely impossible to give a comprehensive set of the social 
properties or facts, especially since they change over time. ${ }^{16}$ Strictly speaking, the ontological individualist holds that all social facts, objects, properties, or events are exhaustively built out of individualistic ones. But if there is any place in the claim where we can tolerate vagueness, it is this one. To draw an analogy, we do not have a clear sense of the set of mental properties, but if we can conclude the beliefs, desires, pains, and so on supervene on neurophysiology, we can develop a reasonable degree of confidence in the more general supervenience thesis. Likewise, even without a comprehensive set of the "social," if we can conclude that markets, prices, GDP, kinship relations, crime levels, elections, languages, and so on supervene on the individualistic, ${ }^{17}$ we can be confident in ontological individualism rather generally.

Probably the best way to approach this part of the thesis of ontological individualism is to look through the social sciences for a nice broad range of social properties and objects. It is also possible to apply ontological individualism is often applied to some specific field or domain of the social sciences. An ontological individualist may be happy, for instance, to restrict her claim to the set of entities referred to in the current macroeconomics literature.

And, of course, if someone aims to deny ontological individualism, she does not need to characterize the set of the "social" at all. She only needs one counterexample, a social fact, object, property, or event that fails to be exhaustively grounded by the individualistic. The more the better, but in principle one counterexample would do.

\subsection{Skepticism about levels}

As I mentioned at the outset, ontological individualism is a thesis in inter-level metaphysics. It is a claim about the relation between entities at the

${ }^{16}$ For instance, new social groups are being formed all the time, as are new types of social groups, new financial instruments, and so on.

${ }^{17}$ Here too, the trick I described in footnote 12 can be used to convert these into corresponding properties. 
social level and entities at the individualistic level. In the above discussion, I have spoken of "high-level” and "low-level” entities, and drawn analogies with the mental and the neural, and with the chemical and the microphysical. There are reasons for being skeptical about this hierarchical picture of distinct levels. Jaegwon Kim, for instance, has argued that we should think of levels as increasingly inclusive sets, where the higher levels include everything at the lower levels and more. ${ }^{18}$ William Wimsatt has argued that the sciences are too interlinked to be arranged in levels at all, and that the closest we can get is different scales of aggregation. ${ }^{19}$ Other worries apply specifically to the individual and the social. Philip Pettit has argued that individual attitudes are partly constituted by social entities, ${ }^{20}$ and many people have argued that the individual is "socially constituted," 21 though often these claims are vague as to whether this is an ontological or a historical claim.

All of these are threats to ontological individualism. If we cannot distinguish the social from the individualistic in the first place, then we cannot clarify the thesis of ontological individualism. Providing satisfactory treatments of the "individualistic base" and the "social facts," as I discussed in 1.2 and 1.3, amount to distinguishing these levels from one another. (Here too, it is more crucial to delineate the individualistic so that it is distinct from the social, than to give a complete account of the social.) If the skeptics about levels are correct, these cannot be achieved, and ontological individualism is no thesis at all.

\section{Anchor individualism}

Nearly all discussion of the role of individuals in "building" the social world has understood it in the terms I have just discussed. There is, however,

\footnotetext{
${ }^{18}$ Kim 2002

${ }^{19}$ Wimsatt 1994

${ }^{20}$ Pettit 1993

${ }^{21}$ Foucault 1970 and many others.
} 
an entirely distinct thesis about this role: the thesis that social facts are exhaustively anchored by individualistic facts.

To introduce the idea of anchoring, consider the recycling bin in front of my apartment. In my town, the bins designated for recycling are large blue plastic cans. Black cans are for non-recyclables. This is not a natural fact about the cans, or a matter of their intrinsic functionality. A black can would work as well for recycling as a blue one. But as it is, when I throw recyclables into the black can or non-recyclables into the blue one, my neighbors scowl at me. And if the city catches me, I am fined.

What makes it the case that blue cans are recycling bins, and black ones bins for non-recyclables? The most widely discussed approach to such questions is John Searle's treatment of "institutional facts” in The Construction of Social Reality (1995) and Making the Social World (2010). The reason being a large blue plastic can is the condition for being a recycling bin, Searle argues, is that we collectively accept a constitutive rule for recycling bins. A constitutive rule is a formula like: ${ }^{22}$

(R) If $\mathrm{x}$ is a large blue plastic can on the sidewalk, then $\mathrm{x}$ is a recycling bin. When the members of a community take a certain attitude toward (R) - in particular, when each member accepts $(\mathrm{R})$ as holding for the community - all the blue plastic cans on our sidewalks count as recycling bins. Notice that, in this account, there are two very different kinds of facts that make the can in front of my apartment a recycling bin. One fact is that the can in front of my apartment is a large blue plastic can. This is the antecedent of (R). The second fact is the fact about collective acceptance, i.e., that the community collectively accepts (R).

Searle's is one of many theories of how principles like (R) are anchored i.e., how the conditions for being a social entity like a recycling bin are put in place. In Searle's theory, they are anchored by collective acceptance. Historically, there have been many alternative theories aiming at a similar

${ }^{22}$ This is a simplified version. Searle proposes a couple of versions in Searle 1995 and refinements in Searle 2010. See Hindriks 2008, Thomasson 2003, and Epstein forthcoming, for criticisms of Searle's formulation. 
target. Hume, for instance, proposed that principles like (R) are conventions, and gave a rudimentary account of them. A convention is, for Hume,

a sense of common interest; which sense each man feels in his own breast, which he remarks in his fellows, and which carries him, in concurrence with others into a general plan or system of actions, which tends to public utility. ${ }^{23}$

Hume is not as explicit as Searle is about distinguishing the fact that a principle like (R) is in place, from the facts that anchor (R). Hume uses the term 'convention' ambiguously, to denote both the beliefs and regularities that give rise to a principle like (R), and to denote the principle itself, that the beliefs and regularities give rise to. ${ }^{24}$ But the key place where Searle differs from Hume is above all in his theory of anchoring, and to a small extent in how to think of and formulate principles like (R).

Another alternative is H.L.A. Hart's theory of laws, in The Concept of Law. ${ }^{25}$ The (R)-like principles Hart theorizes about are of course laws, not constitutive rules or conventions. His "practice” theory is similar in some ways to Hume's theory, and in some ways similar to Searle's. Like Searle, he insists that we have attitudes toward (R) itself, not just toward regularities of activity. But like Hume, he also takes regularities of practice to be conditions for a principle like ( $\mathrm{R})$ to be anchored.

All of these views take social facts and properties to be the products of humans, but in a different way from how the Senate or a soccer team are "composed" of people or "constituted" by people. My recycling bin is not composed of people; it is composed of blue plastic. Nor is it a fiction, or composed of my thoughts or attitudes. My attitudes are weightless, but the recycling bin is heavy. In any of these theories, the two different kinds of facts - i.e., the blue-plastic-can facts vs. the collective-attitude facts, or the

${ }^{23}$ Hume 1777 / 1975, p. 257

${ }^{24}$ Hume regards his formula as a kind of analysis of what a convention is. Lewis and other theorists of convention also tend to use the term ambiguously, for the same reason.

${ }^{25}$ Hart 1962 
blue-plastic-can facts vs. the belief-and-regularity facts — play very different roles.

I suggest we think about anchors in the following way. The facts that anchor principles like (R) - whether collective attitudes, beliefs and regularities, practices, or ideas — set up a kind of "frame" or "context." In that "frame," social facts are grounded in conformance to principle (R). That is, if $(\mathrm{R})$ is anchored for us, then all it takes for something to be a recycling bin is for it to be a large blue plastic can on the sidewalk. In short, the "anchoring facts" set up principles like (R), and principles like (R) give the grounding conditions, for social facts to be the case.

For example, suppose that Hume's theory of anchoring is correct: certain beliefs and regularities of practice set up a frame in which, wherever there is a large blue plastic can on the sidewalk, there is a recycling bin. That is, these beliefs and regularities of practice anchor a principle like (R), a principle that is true throughout the frame. Searle calls his particular version of principles like (R) "constitutive rules." But to broaden the idea to include views such as Hume's and Hart's, I will more generically call these "frame principles." Figure 1 depicts the relationships among the various facts I have described, using a Hart-style theory of anchoring as an illustration:

\begin{tabular}{|c|c|c|}
\hline & & $\begin{array}{l}\text { There is a recycling bin on the sidewalk } \\
\text { in front of my apartment. } \\
\qquad \uparrow \text { grounds }\end{array}$ \\
\hline $\begin{array}{l}\text { A1: We accept the principle } \\
\text { that large blue plastic cans on } \\
\text { the sidewalk are recycling bins. }\end{array}$ & & $\begin{array}{l}\text { G1: There is a large blue plastic can on } \\
\text { the sidewalk in front of my apartment. }\end{array}$ \\
\hline $\begin{array}{l}\text { A2: We regularly treat large } \\
\text { blue plastic cans on the } \\
\text { sidewalk as recycling bins. }\end{array}$ & anchors & $\begin{array}{l}\text { (R) If } x \text { is a large blue plastic cans on the } \\
\text { sidewalk, then } x \text { is a recycling bin. }\end{array}$ \\
\hline
\end{tabular}

Figure 1. Depicting anchors and grounds for a social fact

At the left are the facts $\{A 1, A 2\}$ that anchor the frame principle (R). That is, according to a Hart-style theory, facts about our attitudes towards (R) and practices conforming to it by members of the community. At the right, the bottom of the box gives the frame principle $(\mathrm{R})$. And within the frame is a set of 
facts $\{\mathrm{G} 1\}$ about a blue plastic can on my sidewalk, which in the frame ground the fact that there is a recycling bin on my sidewalk.

For one more example, consider the fact Obama is President of the U.S. In order to be President, one must be at least 35 years old, elected by the Electoral College, take the oath of office, and so on. The frame principle for being President of the U.S. is therefore something like:

(P) If $\mathrm{x}$ is a person who is at least 35 years old, was elected by the Electoral College in the last four years, and has taken the oath of office, then $\mathrm{x}$ is President of the U.S.

Here also, we need to distinguish two kinds of facts. There are facts that anchor the frame principle (P), such as historical facts about the U.S. Constitution or our attitudes towards it. And there are facts within our frame that ground the fact that Obama is President of U.S., such as the fact that Obama is at least 35 years old.

\subsection{The general thesis}

In describing ontological individualism, I pointed out that it is a thesis about social facts in general being built out of facts about individual people. Similarly, anchor individualism is a thesis about how principles like (R) and (P) are anchored in general: namely, by facts about individual people. Searle's collective acceptance theory, for instance, is a theory about how all constitutive rules must be anchored. Whenever a constitutive rule is anchored in a community, it is anchored by the "we-attitudes" of individuals in the community. Searle's basic theory, ${ }^{26}$ in fact, gives us a reductive account of the anchors for any given constitutive rule: Constitutive rule $x$ holds in a community $c$ if and only if every member of $c$ has the we-attitude: We accept $x$.

Similar to ontological individualism, however, this is more than we need, if we only want to argue that anchors in general must be individualistic. A theory of convention, for instance, may take there to be a diverse set of facts that together anchor a variety of conventions. It may not regard conventions as

${ }^{26}$ Searle has modified this a bit in Searle 2010, with his discussion of collective recognition. 
being anchored one by one. It may be, for instance, that we have a huge number of conventions about driving cars, and that all of these conventions are jointly anchored by a huge set of interconnected behaviors and beliefs about driving. Just as ontological individualism is the generic thesis that social facts are exhaustively built out of facts about individuals, anchor individualism is the generic thesis that the grounding conditions for social facts are exhaustively anchored by facts about individuals. That is, it is a claim about a relation holding between a set of "social-level principles" and a set of "individual-level

stuff." And as with the thesis of ontological individualism, if we want to be more precise about the thesis, we need to clarify three topics.

(1) What the exhaustive anchoring relation is, that holds between the social-level principles and the individual-level stuff

(2) What the individualistic base is: individual people, their mental states, their actions, habits, or practices, various relations among them, etc.

(3) What the frame principles are, that are anchored by the base. Are they constitutive rules for institutional facts, social conventions for social kinds, formally enacted laws, or something else?

\subsection{The exhaustive anchoring relation between sets}

The intuitive idea of anchor individualism is simple. Take a set $\mathrm{S}$ of frame principles for social facts, which might include principles like (R) and (P). We want to say that anchor individualism is true just in case all the principles in $\mathrm{S}$ are exhaustively anchored by individualistic facts.

To specify this more carefully, we can introduce a relation similar to supervenience, but that ranges across different "frames." The various supervenience relations are used to capture the notion that once the "supervenience base" is fixed, then that fixes the "supervening" properties or facts. Similarly, here we want to capture the notion that if we fix the set of individualistic anchoring facts, then we fix the frame principles $\mathrm{S}$.

Thus we need to recognize that there are many different ways of "framing" the world. In Figure 1, a single frame principle was depicted, along with its anchors. But to make a claim about anchors in general, we need to think about the range of all frames. This is depicted in Figure 2: 


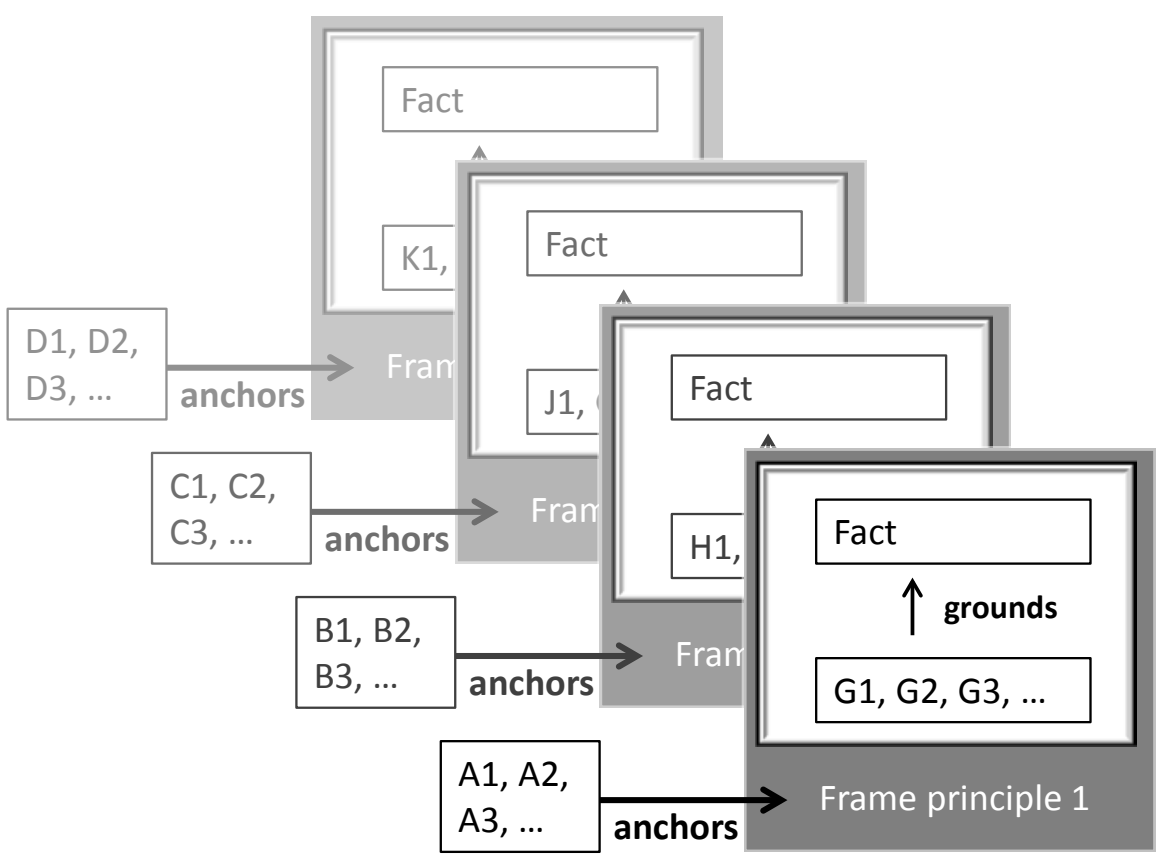

Figure 2. Depicting multiple frames

Each of the sets of anchors, $\{A 1, A 2, \ldots\},\{B 1, B 2, \ldots\}$, etc., is a set of facts. We might think of $\{A 1, A 2, \ldots\}$ as a set of facts holding at one time, such as the year 1950, $\{\mathrm{B} 1, \mathrm{~B} 2, \ldots\}$ as holding at a different time, such as 1975, and so on. Or we might think of $\{\mathrm{A} 1, \mathrm{~A} 2, \ldots\}$ as holding in one community such as the U.S., and $\{\mathrm{B} 1, \mathrm{~B} 2, \ldots\}$ as holding in a different community, such as Mexico. Or we might think of them as holding in different "worlds," in a possible worlds framework. Or we might think of them as iterated: $\{\mathrm{A} 1, \mathrm{~A} 2, \ldots\}$ is a set of facts in the frame anchored by $\{\mathrm{B} 1, \mathrm{~B} 2, \ldots\}$, and $\{\mathrm{B} 1, \mathrm{~B} 2, \ldots\}$ is a set of facts in the frame anchored by $\{\mathrm{C} 1, \mathrm{C} 2, \ldots\}$, and so on.

Each of these sets of facts serves to anchor the frame principles in its corresponding frame. Suppose, for instance, that the following are anchors for two different frames:

A1: We accept the principle that large blue plastic cans on the sidewalk are recycling bins.

A2: We regularly treat large blue plastic cans on the sidewalk as recycling 
bins.

B1: We accept the principle that small green metal cans on the sidewalk are recycling bins.

B2: We regularly treat small green metal cans on the sidewalk as recycling bins.

Thus $\{\mathrm{A} 1, \mathrm{~A} 2\}$ anchors principle $(\mathrm{R})$, whereas $\{\mathrm{B} 1, \mathrm{~B} 2\}$ anchors $\mathrm{a}$ different principle in that set's respective frame.

Searle claims that the only way to anchor a constitutive rule is by collectively accepting that rule. This means that across all possible frames, facts about collective acceptance are necessary and sufficient for fixing the frame principles. Another way of putting it is this: once we fix the facts about what is collectively accepted in the anchoring context, we have thereby fixed the facts about what constitutive rules are anchored by that context.

This is a way we might begin understanding an "exhaustive anchoring" claim. Similar to a supervenience claim, it asserts that once we have fixed a certain kind of anchoring fact, that suffices to fix a kind of fact anchored by it. Technical machinery for this can be developed, as it has been for supervenience. Clarifying the exhaustive anchoring relation is the first step in interpreting the claim that constitutive rules are exhaustively anchored by collective acceptance, or that conventions are exhaustively anchored by beliefs and regularity of activity, or more generally that frame principles for social facts are exhaustively anchored by individualistic facts.

\subsection{The individualistic base}

Although there are many theories of anchoring in circulation, it is rare to consider the set of facts in general that serve to anchor frame principles. As I described in connection with ontological individualism (in section 1.2), some people think about individualistic properties as mental or psychological properties. Among theorists of anchoring, many people (including Searle) think of the anchors for social facts as mentalistic. They regard social facts as a kind of "projection" by the mind onto the natural world. Other views of anchoring, as I mentioned, involve practices or activities as well as mental states. Hume's theory of convention and Hart's "practice theory” of law may 
be counted among these. As with ontological individualism, it must be decided, to make anchor individualism precise, which properties or facts count as the individualistic ones.

A similar pattern emerges as we saw with ontological individualism. The facts that count as individualistic surely include at least certain mental facts about individual people. If a wholly mentalistic theory of anchoring, like Searle's, is correct, then the thesis of anchor individualism is straightforwardly true as well. On the other hand, Hume's “regularities" and Hart's "practices" are not intrinsic to individual people. Therefore, if one of these theories of anchoring is correct, we have to make a choice. We either need to expand the individualistic base, so as to include practices among the individualistic facts, or else the theory is a counterexample to anchor individualism.

Here too, it is a delicate matter whether to expand the individualistic base. It seems foolish to reject anchor individualism only because we have chosen an excessively strict notion of "individualistic." On the other hand, it also seems foolish to be so committed to anchor individualism that we will expand the individualistic base indefinitely, to the point that the thesis becomes empty.

\subsection{The frame principles for social facts}

The thesis of anchor individualism holds, generically, that all frame principles for social facts are exhaustively anchored by individualistic facts. To be precise, it is not the social facts like The blue plastic can on my sidewalk is a recycling bin or Obama is President that are anchored in a community's frame. Instead, it is frame principles like (R) or (P). Nonetheless, corresponding to any social fact (like Obama is President) is one or more frame principles (like (P)). So an intuitive approach to think about the set of frame principles is to work from the set of social facts discussed in section 1.3. Assume that frame principles have a certain form, such as If facts of type $X 1, \ldots, X n$ are the case, then fact $Y$ is the case. The frame principles for social facts are those that have the social facts from 1.3 in the "Y" position.

As with ontological individualism, anchor individualism can be applied to some specific sub-domain of the social sciences. Indeed, particular theories of anchoring are often held to be theories of some particular sort of frame 
principle. Searle's collective acceptance theory is a theory of anchoring for constitutive rules, having a certain form. These constitutive rules are the frame principles for certain kinds of social facts, ones that Searle calls "institutional facts." Hume's theory is, of course, a theory of convention. Hume applies his theory to standard examples of social properties, such as ownership, money, and language, but does not say whether all conventions give rise to social facts or institutions, or if only some do, and conversely whether all social facts or institutions are conventional. And Hart's is a theory of laws.

\section{Comparing the two}

Ontological individualism is a thesis about the grounds of social facts within our frame, and anchor individualism is a thesis about how frames in general (including ours) are anchored. Having sketched these two theses, the natural question to ask is whether they are actually distinct from one another. In particular, are anchors just more grounds? For example, suppose Searle's theory is correct, and constitutive rule $(\mathrm{P})$ is anchored by collective acceptance of (P) in the community. Then shouldn't we just say that the fact Obama is President of the U.S. is grounded by both the facts like Obama was elected by the Electoral College and by facts like We collectively accept $(P)$ ? This idea is depicted in Figure 3, as an alternative to depictions in Figures 1 and 2.

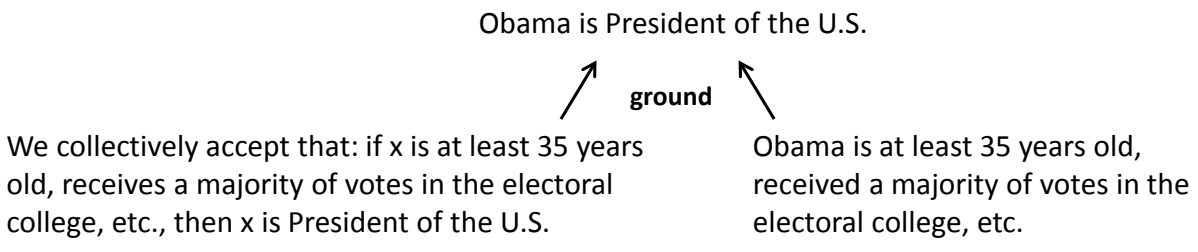

Figure 3. Treating anchors as more grounds

After all, it seems that the collective acceptance fact is just part of the supervenience base of the fact Obama is President of the U.S. If we did not collectively accept (P), that fact would not be the case.

This, I propose, is the wrong way to think about the relation between anchors and grounds. The kind of counterfactual I just mentioned — if we did 
not collectively accept $(P)$, Obama would not be President - is more subtle than it seems. In one sense, it can be evaluated as comparing the actual frame with a counterfactual frame. Comparing one frame with another, it is correct to say that if we collectively accepted a different rule (P'), then Obama would not actually be President. However, in a different sense, the counterfactual can be evaluated inside our frame. Within a frame, for someone to be President only depends on being over 35, voted in by the Electoral College, and taking the appropriate oath. After all, the whole idea of a constitutive rule, law, convention, or other frame principle is that it gives all the conditions for something to have a given social property like being President.

When we assess typical supervenience claims for social facts, we do so inside a frame. Consider, for instance, the property being a senior citizen. This is a social property whose conditions are anchored by social facts - perhaps by law, by convention, by collective acceptance, or by practices. The grounds for being a senior citizen are that one be at least 65 years old. When we evaluate the conditions under which a person may or may not be a senior citizen, we consider different situations, in which the person has a different age. Is the person younger than 65 , or not? If we wanted to, we might also consider situations in which the application conditions for the property changed; for instance, where the body of U.S. law is different. But that is changing the conditions for being a senior citizen. As it is anchored in our frame, the social property being a senior citizen supervenes on the age properties of individual people, and that alone.

I do not intend to mount a sustained defense of this claim, in this paper. I do want to point out, however, that the defender of either form of ontological individualism should be an even more insistent advocate for distinguishing anchors from grounds. Consider how Figure 3 looks, as applied to the example of the recycling bin. This is depicted in Figure 4: 
There is a recycling bin on the sidewalk in front of my apartment.

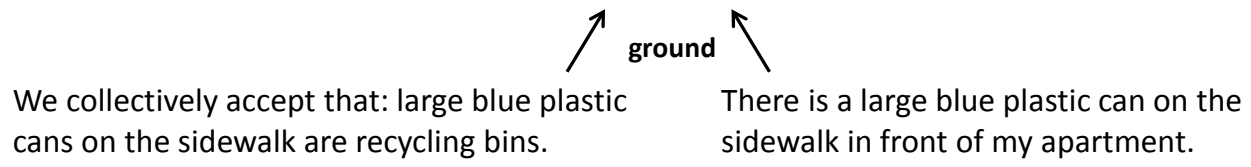

Figure 4. Treating the anchors for $(R)$ as just more grounds

In Figure 4, the social fact The can in front of my apartment is a recycling bin is depicted as being grounded by facts about our attitudes together with facts about blue plastic. That is, it is depicted as being grounded by - to put it in Searle's terminology — both "intentional facts" and "brute facts." But Searle would not suggest that the "brute facts" must be individualistic. The key idea of his theory is that individual attitudes project features onto the brute world of non-persons.

The anchor individualist in general has a stake in keeping the grounds like being a blue plastic can separate from the individualistic anchors. The typical anchor individualist will have no interest in being a ontological individualist, and will reject the thesis that social facts supervene on individualistic ones. Because whether we collapse the anchors into the grounds, or keep the grounds separate, a property like being a recycling bin depends at least in part on the property being a blue plastic can.

Conversely, the ontological individualist will take issue with the perspective of anchor individualism. The ontological individualist insists that non-individualistic facts have no place in grounding social ones. This means that she may restrict the set of social facts, so as to exclude facts like There is a recycling bin in front of my apartment. She may be an ontological individualist about macroeconomic facts, for instance, but not recycling facts. Or else she may expand the individualistic base, so that a property like being a large blue plastic can in front of my house is an individualistic fact about me or other people. 


\section{Conclusion}

To many people, both ontological individualism and anchor individualism seem to be appealing for the same reason. Both seem to deflate worries about the "reality" of the social world. The social world is just us, both theses hold. However, the two theses deflate these worries in conflicting ways. For an ontological individualist, the prototypical example of a social fact is one about a group, like a court or legislature, which is composed of individual people. The ontological individualist typically regards social facts as emerging from interactions among individual people, in combination with one another. For an anchor individualist, in contrast, the prototypical example is a fact about dollar bills, recycling bins, or boundaries made of lines of stones.

Advocates of explanatory individualism will favor ontological individualism. Although ontological individualism does not imply explanatory individualism, it is at least a first step. If facts about a mob are exhaustively grounded by facts about individual people, then there is a chance that we can explain those facts in terms of facts about individual people.

Anchor individualism, on the other hand, is not as congenial to explanatory individualism. Suppose, for instance, that one is an anchor individualist but not an ontological individualist about the fact There is a recycling bin in front of my apartment. That is, this fact does not supervene on individualistic facts, but the frame principles for recycling bins, apartments, etc., are exhaustively anchored by individualistic facts. When we are explaining this fact — giving a causal or other kind of explanation for why it is the case - its supervenience failure means that it is very unlikely that that explanation can be given entirely in terms of facts about individual people. Instead, the explanation will in all likelihood need to involve some of the non-individualistic facts that actually ground it. Some people seem to think that if constitutive rules (or other frame principles) for money or recycling bins are anchored by attitudes, then money and recycling bins are just "in the head," like fictional characters in a mental play. But again, recycling bins are heavy, and made of plastic. Even if their frame principles are anchored by attitudes, facts about them are grounded by facts about things other than attitudes. 
Altogether, ontological individualism and anchor individualism are very different from one another. Discussions in the metaphysics of the social world are often enormously confused, because of the failure to notice this difference, or to see its magnitude.

\section{References}

Bennett, K. (2011). Construction Area: No Hard Hat Required. Philosophical Studies, 154, 79-104.

Correia, F. (2005). Existential Dependence and Cognate Notions. Munich: Philosophia Verlag.

Currie, G. (1984). Individualism and Global Supervenience. British Journal for the Philosophy of Science, 35, 345-58.

Epstein, B. (2008). When Local Models Fail. Philosophy of the Social Sciences, 38, 3-24.

(2009). Ontological Individualism Reconsidered. Synthese, 166(1), 187-213.

(2011). Agent-Based Models and the Fallacies of Individualism. In P. Humphreys and C. Imbert (Eds.), Models, Simulations, and Representations (pp. 115-44). New York: Routledge.

(forthcoming). Social Objects Without Intentions. In A. Konzelmann

Ziv, H. B. Schmid and U. Schmid (Eds.), Collective Intentionality and Social Ontology. Berlin: Springer.

Fine, K. (2001). The Question of Realism. Philosopher's Imprint, 1(1), 1-30.

Foucault, M. (1970). The order of things: an archaeology of the human sciences. London: Tavistock Publications. 
Hart, H. L. A. (1962). The Concept of Law. Oxford: Clarendon Press.

Hindriks, F. (2008). The Status Account of Corporate Agents. In H. B. Schmid, K. Schulte-Ostermann and N. Psarros (Eds.), Concepts of Sharedness: Essays on collective intentionality (pp. 119-44). Frankfurt: Ontos.

Hodgson, G. (2007). Meanings of Methodological Individualism. Journal of Economic Methodology, 14(2), 211-26.

Hume, D. (1777 / 1975). Enquiries Concerning Human Understanding and Concerning the Principles of Morals. In: L. A. Selby-Bigge, ed., Oxford: Clarendon Press.

Kim, J. (1998). Mind in a Physical World. Cambridge: MIT Press.

_ (2002). The Layered Model: Metaphysical Considerations. Philosophical Explorations, 5(1), 2-20.

Kincaid, H. (1986). Reduction, Explanation and Individualism. In M. Martin and L. C. McIntyre (Eds.), Readings in the Philosophy of Social Science (pp. 497-515). Cambridge: MIT Press.

Lukes, S. (1968). Methodological Individualism Reconsidered. British Journal of Sociology, 19, 119-29.

McLaughlin, B. and K. Bennett (2005). Supervenience. In: E. Zalta, ed., Stanford Encyclopedia of Philosophy.

Pettit, P. (1993). The Common Mind. New York: Oxford University Press.

Putnam, H. (1975). The Meaning of 'Meaning'. Philosophical Papers. Cambridge: Cambridge University Press.

Rosen, G. (2010). Metaphysical Dependence: Grounding and Reduction. In B. Hale and A. Hoffman (Eds.), Modality: Metaphysics, Logic, and Epistemology. Oxford: Oxford University Press.

Schaffer, J. (2009). On What Grounds What. In D. Manley, D. J. Chalmers and R. Wasserman (Eds.), Metametaphysics: New Essays on the Foundations of Ontology. Oxford: Oxford University Press. 
Searle, J. R. (1995). The Construction of Social Reality. New York: Free Press. (2010). Making the Social World: The structure of human civilization. Oxford: Oxford University Press.

Thomasson, A. (2003). Foundations for a Social Ontology. ProtoSociology, 18-19, 269-90.

Weatherson, B. (2006). Intrinsic vs. Extrinsic Properties. Stanford Encyclopedia of Philosophy.

Wimsatt, W. (1994). The Ontology of Complex Systems: Levels of Organization, Perspectives, and Causal Thickets. Canadian Journal of Philosophy, Supplement Vol. 20, 207-74.

Zahle, J. (2006). Holism and Supervenience. In S. P. Turner and M. Risjord (Eds.), Philosophy of Anthropology and Sociology (pp. 311-42). Amsterdam: North Holland. 